\title{
Retraction Note to: Technical Features and Challenges of the Paper-Based Colorimetric Assay
}

Dongtak Lee, Insu Kim, Sang Won Lee, Gyudo Lee, and Dae Sung Yoon

\section{Retraction Note to:}

\section{Chapter "Technical Features and Challenges}

of the Paper-Based Colorimetric Assay" in: J. H. Lee (ed.), Paper-Based Medical Diagnostic Devices, Bioanalysis 10, https://doi.org/10.1007/978-981-15-8723-8_4

This Chapter has been retracted at the request of the Dae Sung Yoon due to significant overlap with a publication by different authors [1].

All authors agree to this retraction.

[1] Morbioli, G. G., Mazzu-Nascimento, T., Stockton, A. M., \& Carrilho, E. (2017). Technical aspects and challenges of colorimetric detection with microfluidic paper-based analytical devices ( $\mu$ PADs)-A review. Analytica chimica acta, 970, 1-22. https://doi.org/10.1016/j.aca.2017.03.037

The book has been updated with change. 